\title{
A Novel Bio-Eco Technology Combined System for Rural Domestic Wastewater Treatment in a Tourism Area: A Full-Scale Study
}

\author{
Hanwen Liang,, Junxin Liu, ${ }^{1, *}$ Xuesong Guo,, Baoqing Shan, Jingzhu Zhao, \\ Lijun $\mathrm{Yu}^{2},{ }^{2}$ Lichuan Li, ${ }^{3}$ and Jianjun $\mathrm{Liu}^{2}$ \\ ${ }^{1}$ Research Center for Eco-Environmental Sciences, Chinese Academy of Sciences, Beijing, People's Republic of China. \\ ${ }^{2}$ Lugu Lake Tourism Area Management Committee, Lijiang, People's Republic of China. \\ ${ }^{3}$ Bureau of Environmental Protection of Lijiang, Lijiang, People's Republic of China.
}

Received: February 5, $2009 \quad$ Accepted in revised form: June 12, 2009

\begin{abstract}
Characteristics of rural water consumption and sewage discharge in a tourism area were determined through an investigation of local villages in Lugu Lake (Yunnan Province). Based on the results of this evaluation, a novel bio-eco technology combined system was developed for high-quality wastewater treatment and recycling at low cost in the rural area. In this combined system, the bio-technique unit is an integrated oxidation ditch with vertical circle (IODVC), and the eco-technique unit consists of a wetland eco-filter, a subsurface infiltration and an eco-ditch. A full-scale wastewater treatment plant of this combined system was built in Lige Village, which is located at the Lugu Lake Tourism Area. The performance of the bio-eco combined system showed that its effluent quality reached up to grade III of the surface water standards (GB3838-2002), that is, the concentration of chemical oxygen demand (COD), ammonia nitrogen $\left(\mathrm{NH}_{4}{ }^{+}-\mathrm{N}\right)$, and total phosphorus (TP) in final effluent was less than 10, 1, and $0.1 \mathrm{mg} / \mathrm{L}$, respectively, whereas the COD of $140-300 \mathrm{mg} / \mathrm{L} \mathrm{NH}_{4}{ }^{+}-\mathrm{N}$ of $40-70 \mathrm{mg} / \mathrm{L}$, and TP of $3-5 \mathrm{mg} / \mathrm{L}$ in the influent, respectively. Furthermore, evaluation of the P adsorption of the local soil revealed that the $\mathrm{P}$ was removed by the ecological treatment unit of the bio-eco combined system via the fixation and sorption of iron and aluminium in the soil. The effluent of the full-scale wastewater treatment plant was used as the source water of a local landscape ecological wetland. Results demonstrated that this bio-eco combined system could be a feasible technology for wastewater treatment in this kind of rural areas.
\end{abstract}

Key words: rural wastewater treatment; bio-eco system; integrated oxidation ditch with vertical circle (IODVC); eco-filter; subsurface infiltration

\section{Introduction}

E NVIRONMENTAL POLLUTION PROBLEMS in rural areas have become more serious as rapid economic development occurred in China. Indeed, it has been reported that over $96 \%$ of the villages in China have no sewage facilities or wastewater treatment systems (MHURDPRC, 2005). As a result, a large amount of domestic sewage is discharged directly into public waters, which has threatened the local aquatic environment (Tang et al., 2008). The characteristics of rural wastewater are often decentralized, changing greatly in quality and quantity; therefore, the conventional wastewater treatment technology and operation mode used in municipal

${ }^{*}$ Corresponding author: State Key Laboratory of Environmental Aquatic Chemistry, Research Centre for Eco-Environmental Sciences, Chinese Academy of Sciences, Beijing 100085, P.R. China. Phone: +86-10-62849133; Fax: +86-10-62849108; E-mail: jxliu@rcees .ac.cn wastewater treatment are not suited for rural areas (Ho, 2003). Currently, a combination of biological technologies and ecological methods is widely used for decentralized wastewater treatment in rural areas worldwide (Kavanagh and Keller, 2007), including septic tank, contact oxidation, oxidation ditch, sequence batch reactor (SBR), and soil infiltration (Quan et al., 2005). Decentralized wastewater treatments are generally pipeline cost saving, easy to maintain, and convenient to reuse (Ho, 2003; Voorthuizen et al., 2005). A septic tank is generally not used as an independent process due to unqualified effluent (Oladoja and Ademoroti, 2006). The biotricking filter has been gradually applied in rural areas in China due to its simplicity, low costs of construction, and operation (Bai and $\mathrm{Wu}, 2005)$. The SBR, which produces the high-quality effluent, has a compact structure and operates stably, has been widely used for treating decentralized wastewater in Europe (Hellstrom and Jonsson, 2003). However, the application of SBR is limited in China due to its high energy consumption, high operation cost, and complicated 
maintenance (Liu and Chu, 2007). Soil infiltration combined with a septic tank is a much more common process for rural wastewater treatment in China (Kong et al., 2006). However, the results of our investigation in some rural areas showed that shallow groundwater was polluted near the septic tank; especially, the total Escherichia coli was over 100 times higher than the ground water quality standard of China (MGMPRC, 1994).

Rural wastewater treatment seems simple, but it is difficult in practice. Wastewater treatment systems in rural areas should use as much as possible of the local natural and environmental conditions, be easy to maintain, and conduct to save the costs of construction and operation, because such areas often have poor economies and the residents often do not have the expertise to operate complex systems (Ho, 2003). In addition, the wastewater treatment systems should have high treatment efficiency to improve the rural environment.

The characteristics of rural wastewater in a tourism area differ with the generic rural areas on two facts. First, the number of tourists visiting a tourism area varies seasonally; as a result, the quantity of wastewater varies greatly. Second, it is necessary to ensure that the effluent of wastewater treatment system meets more stringent criteria than that of the generic rural areas. Therefore, the rural wastewater treatment system used in a tourism area should possess some excellences of high-quality effluent, low cost of construction and operation, suiting a great change of wastewater quantity. The purpose of this study was to develop a novel bio-eco combined system for rural wastewater treatment in a tourism area, and investigate its performance through a full-scale plant experiment.

\section{Materials and Methods}

\section{Study area and background}

This study was conducted in Lige Village in the Lugu Lake Tourism Area in Yunnan Province (Fig. 1). As a typical plateau lake and a famous tourist site, Lugu Lake lies on the boundary between Yunnan and Sichuan Province at an altitude of $2690.8 \mathrm{~m}$, and is surrounded by mountains. The lake is horseshoe shaped, $9.5 \mathrm{~km}$ long from south to north, $5.2 \mathrm{~km}$ long from east to west, $93.5 \mathrm{~m}$ at its deepest position, and has an average depth of $40.3 \mathrm{~m}$. The water area is $50.1 \mathrm{~km}^{2}$, the total catchment area of the lake is $247.6 \mathrm{~km}^{2}$, and the inflow is 67 million tons per year. The outflow rate is $3-5 \mathrm{~m}^{3} / \mathrm{s}$ from June to October, very small during November and December, and there is no outflow from January to May. Therefore, Lugu Lake is a semiclosed system. The water quality of Lugu Lake is very good, and there are abundant species of aquatic plants that are not common in other plateau lake in China. Indeed, there are 37 species of aquatic vascular plants in Lugu Lake belonging to 25 genera and 19 families. The plants found in the lake can be divided into three categories: emerged, floating, and submerged. The transparency of Lugu Lake is generally $7-10 \mathrm{~m}$, and the $12 \mathrm{~m}$ depth can be seen in some places. The chemical constituents in the lake water, include calcium $(\mathrm{Ca})$, magnesium, sodium $(\mathrm{Mg})$, phosphorus $(\mathrm{P})$, nitrogen $(\mathrm{N})$, iron $(\mathrm{Fe})$, and organic compounds. Lugu Lake belongs to oligotrophic lake (LLTAMC, 2006).

The population of the area surrounding Lugu Lake was 13,233 in 2006. The local tourism industry has recently been well developed, as indicated by an increase in the number of visitors from 36,000 in 1992 to 500,000 in 2007. Consequently,

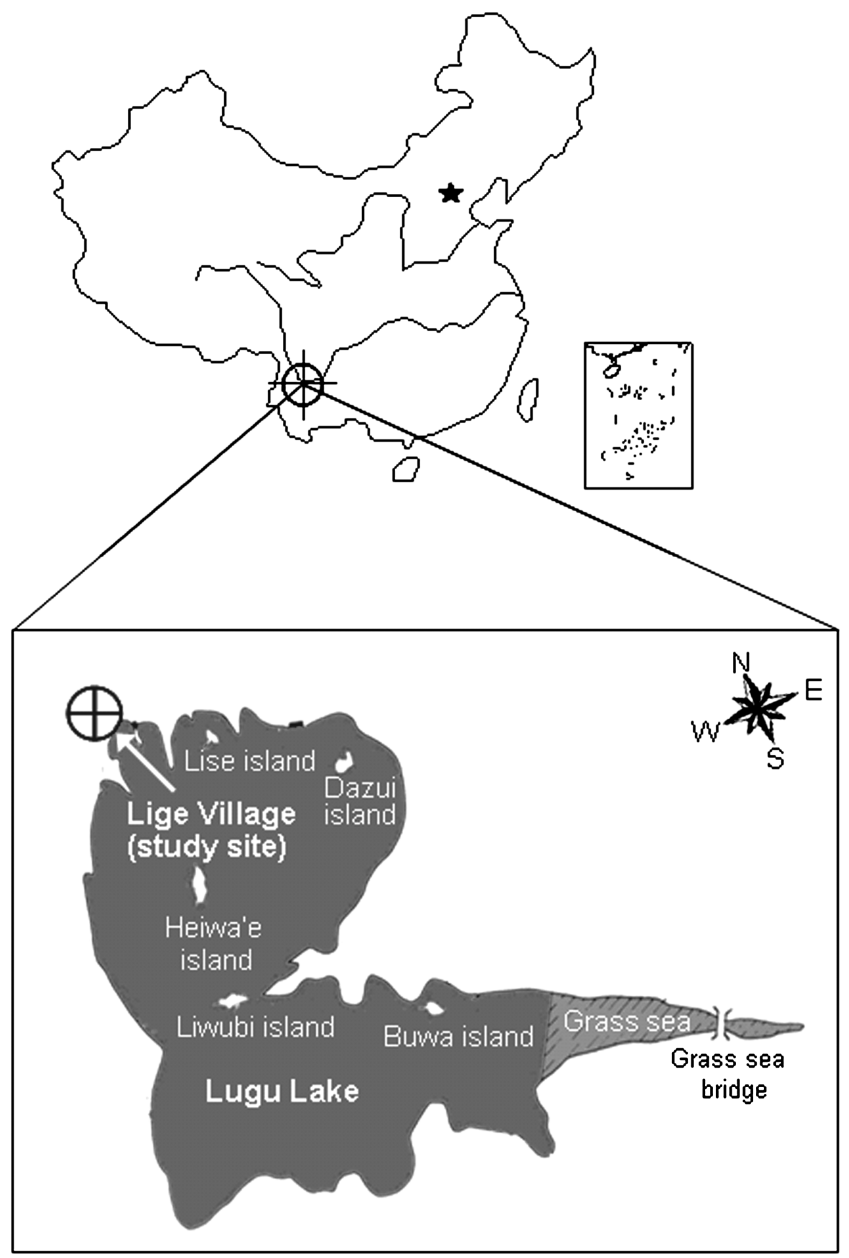

FIG. 1. Map of Lugu Lake area and the study site.

the tourism industry has become a pillar of the local economy (LLTAMC, 2006).

The total quantity of wastewater discharged into Lugu Lake has increased rapidly in response to the rapid increase in tourists. This increase in wastewater has threatened the quality of the lake water, especially along the shore in residential areas. Overall, the eco-environmental problems at Lugu Lake are as follows: (1) no wastewater treatment: with the development of the local tourism industry, a great number of houses, hotels, and restaurants were built near the lake or even on the lakeshore; however, no effective pollution control system was constructed. As a result, the wastewater and garbage were released directly into the lake. (2) Lack of diffuse pollution control: owing to lack of sufficient buffer zone near the lake, diffuse pollution and soil erosion bring threatens the lake water quality. (3) Decreasing of landscape function: channelized stream and artificial lakeshore in some areas of Lugu Lake have been greatly altered, which has resulted in the ecological function becoming seriously degenerated. The source of water pollution in Lugu Lake area includes four types: rural domestic wastewater, tourism industry wastewater, surface runoff, and atmospheric deposition. In addition, the major pollution comes from decentralized point sources, such as domestic wastewater and runoff associated with tourism industry. To protect the natural landscape and aquatic safety from environmental deterioration, the local 


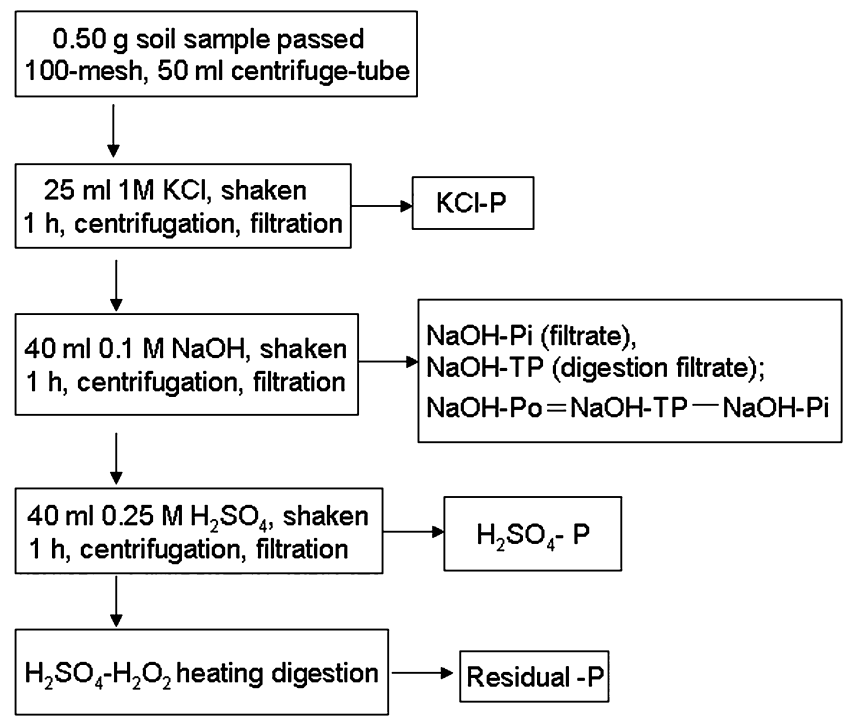

FIG. 2. The phosphorus fraction procedure.

government required to collect and treat prior to discharge. Moreover, according to the criteria established by the local government, all environment management and pollution controls must be designed to maintain the natural landscape and facilitate development of the tourism industry in the Lugu Lake Area.

\section{Investigation of rural wastewater characteristics}

Household surveys, interviews, and sample analysis were carried out in this study. To ensure that the surveys were representative of the sample area, the households were selected using a nonrandom sampling method in which the households were classified according to the difference of local residents production mode and life style and tourists consumption pattern among the households. A representative sample was then selected from each category of households, and utilized as the object of household survey. The classification principle that was utilized as follows: (1) the production mode of local residents and consumption pattern of tourists, (2) the location distribution of households, and (3) the age structure and population scale within a household. In addition, the water consumption was used to determine the quantity of domestic wastewater instead of directly investigating the wastewater produced by a single household.

\section{$P$ adsorption by local soils}

The soil without reclamation near Lugu Lake was sampled, and then the soil sample air dried was passed through 20mesh and 100-mesh sieves, respectively, for the following analysis.

Duplicate 10.0-g samples of the soil were placed in 100-mL polythene centrifuge tubes. Next, $50 \mathrm{~mL}$ of $0.01 \mathrm{M} \mathrm{KCl}$ solution that included an initial $\mathrm{P}$ concentration of $500 \mathrm{mg} \mathrm{P} / \mathrm{L}$ as $\mathrm{KH}_{2} \mathrm{PO}_{4}$ were added to the centrifuge tubes. The sealed tubes were then continuously shaken at $25^{\circ} \mathrm{C}$ and $190 \mathrm{rpm}$ until the supernatant $\mathrm{P}$ concentration was in equilibrium. The supernatants were then removed and the remaining soils were air dried to reduce the water content prior to subsequent analysis. The TP in the raw soil samples was analyzed by the $\mathrm{HClO}_{4}-\mathrm{H}_{2} \mathrm{SO}_{4}$ digestion method (Bao, 2000). The TP of the adsorption saturation samples was the sum of TP in the raw samples and adsorbed P. P fractions of the adsorption saturation soil sample and the raw sample were determined by the following fractions extracted method (Moore and Reddy, 1994; Moore and Coale, 2004). The $\mathrm{P}$ fractions extracted were the exchangeable $\mathrm{P}(\mathrm{KCl}-\mathrm{P})$, iron/aluminum-bound $\mathrm{P}$

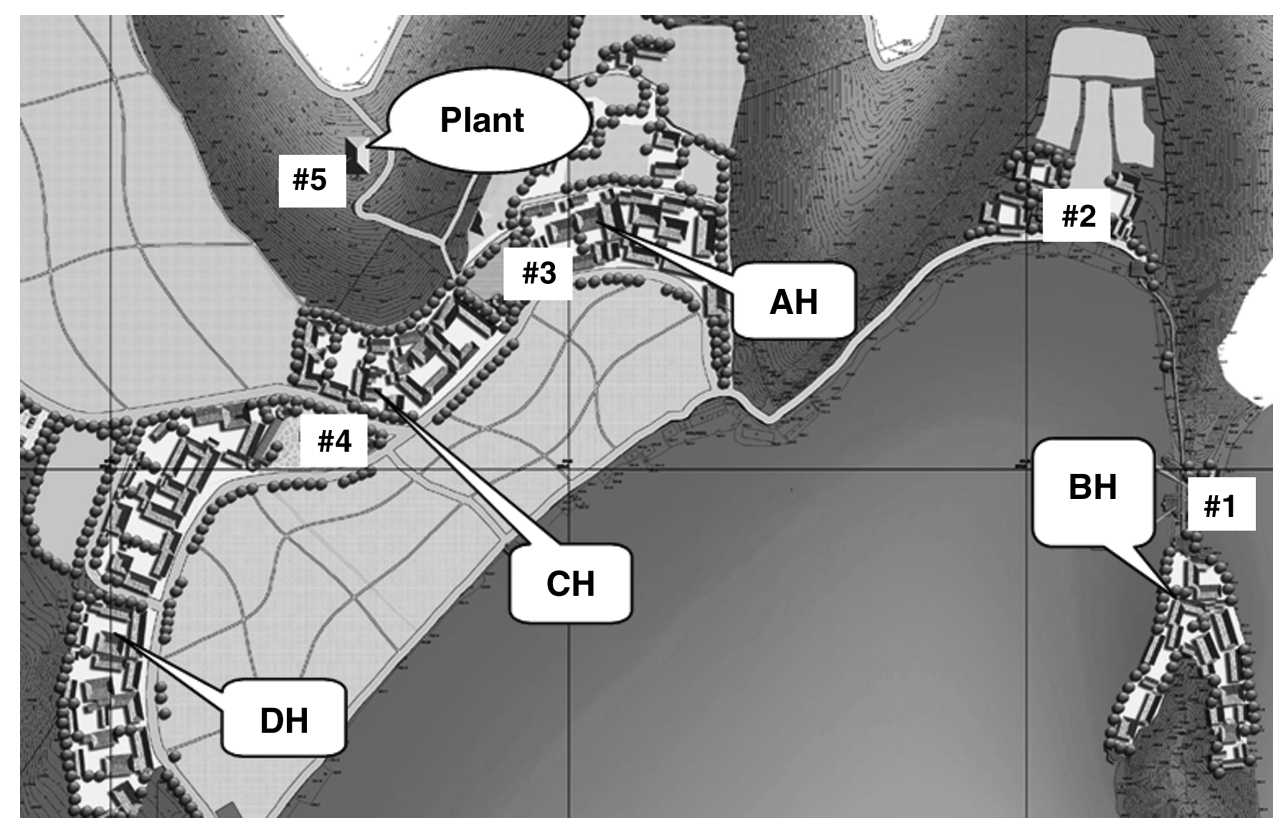

FIG. 3. Location of primary settling tanks and investigated households. $\mathrm{AH}$, aboriginal household; $\mathrm{BH}$, with a simple hotel household; $\mathrm{CH}$, with a shower facility hotel household; $\mathrm{DH}$, with a restaurant household. \#1 to \#5, primary settling tanks. 


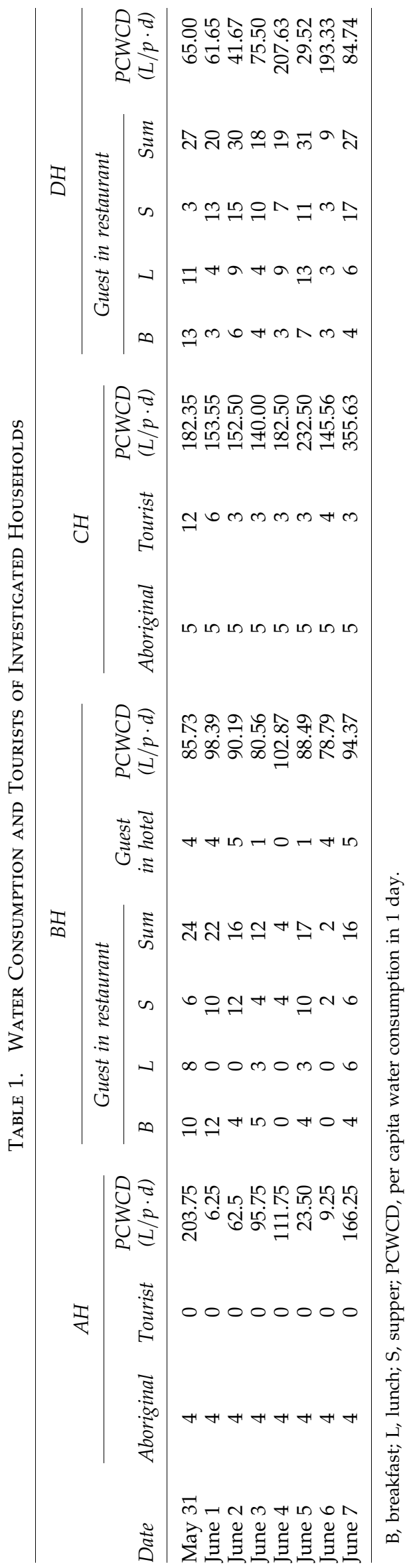

(NaOH-Pi), organic-bound $\mathrm{P}$ (NaOH-Po), calcium-bound $\mathrm{P}$ (Ca-P), and residual $\mathrm{P}$ (Res-P) in sequence according to Fig. 2. The variations among replicates were $<10 \%$ for TP and $\mathrm{P}$ fraction analysis.

\section{Investigation of full-scale wastewater treatment system}

A full-scale wastewater treatment system combining biological and ecological technologies was constructed in Lige Village, which was located on the lakeshore of Lugu Lake. The treatment capacity of the system was $100 \mathrm{~m}^{3} /$ day, but the short peak flow reached as high as $300 \mathrm{~m}^{3} /$ day. Construction of the biological treatment unit in the system was completed in May 2007, and vegetations growth of the ecological treatment unit finished in the spring of 2008. All system has been working continuously since April 2008. The average temperature in Lugu Lake Area is above $15^{\circ} \mathrm{C}$ annually, and the average temperature in winter is around $10^{\circ} \mathrm{C}$ (LLTAMC, 2006; NBSC, 2007).

\section{Analysis method}

The measures of $\mathrm{pH}$ and dissolved oxygen (DO) of wastewater were conducted using WTW pH/Oxi 340i (made in Germany). The type of probe of $\mathrm{pH}$ and DO was WTW $\mathrm{pH}-$ Electrode SenTix 41 and CellOx 325, respectively. The chemical oxygen demand (COD), ammonia nitrogen $\left(\mathrm{NH}_{4}{ }^{+}-\mathrm{N}\right)$, and TP in the influent and effluent of the full-scale plant were monitored regularly (once a week) according to the standard method (APHA, 1998).

The physicochemical properties of the soil samples including organic matter $(\mathrm{OM})$, available $\mathrm{P}$, and $\mathrm{pH}$ were measured according to the standard methods (Bao, 2000). The specific surface area of the raw soil sample was analyzed using the BET protocol (ASAP 2000, Micromeritics Co., Norcross, GA). For $\mathrm{pH}, \mathrm{OM}$, available $\mathrm{P}$, and surface area analysis, the variations within replicates were less than $10 \%$. For Fe, aluminum ( $\mathrm{Al}), \mathrm{Ca}, \mathrm{Mg}$, and manganese $(\mathrm{Mn})$ analysis, the sample was digested with a 5:1 mixture of hydrofluoric and perchloridic acids (Tessier et al., 1979). The solution was then analyzed by an ICP-OES. Recoveries varied but all fell in the range of $90-95 \%$, and the precision was under 3\% relative standard deviation. Amorphous and poorly crystalline $\mathrm{Fe}, \mathrm{Al}$, and Mehlich I-Ca, $\mathrm{Mg}$ of the raw soil samples were analyzed using the oxalic acid-ammonium oxalate and Mehlich I extracting methods, respectively (Pierzynski, 2000). The variations within replicates were $<10 \%$.

\section{Results and Discussion \\ Properties of wastewater in a rural area with a tourism industry}

There are many hotels, restaurants, pubs, and other entertainment places in the Lugu Lake Area. For this study, we selected Lige Village, which was located along the lakeshore, for further investigation. The total area of Lige Village is $533,600 \mathrm{~m}^{2}$, and it contains 36 households, 150 native residents, and 200 migrants. The number of tourists changes seasonally. Four households $(\mathrm{AH}, \mathrm{BH}, \mathrm{CH}$, and $\mathrm{DH})$ belonging to different categories were studied in detail (Fig. 3). The general information regarding each household was as follows: AH contained no construction or facilities associated 


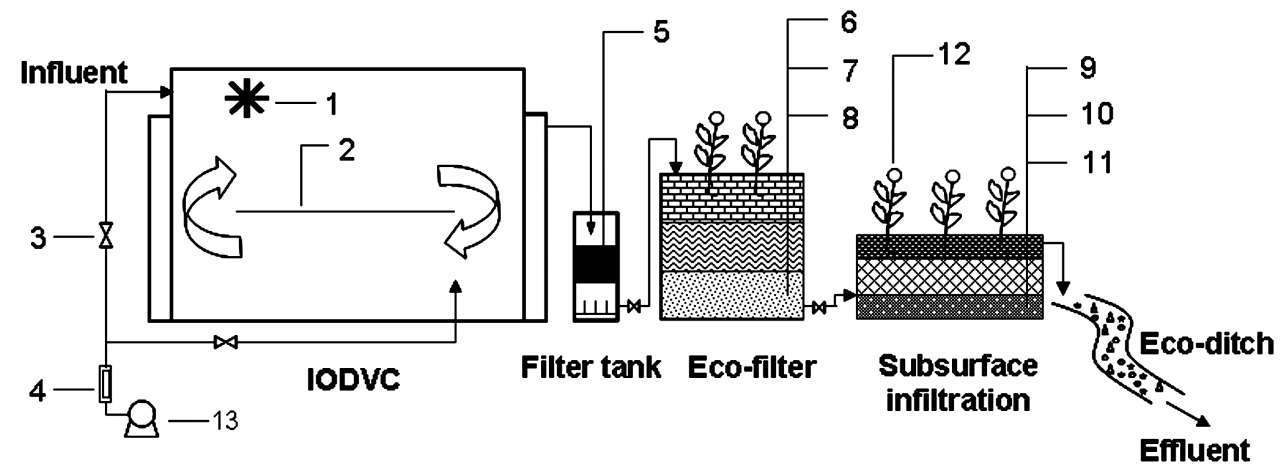

FIG. 4. Scheme of bio-eco combined wastewater treatment system. 1-rotating brush, 2-plate, 3-check valve, 4-liquid flow meter, 5-ceramisite, 6-soil, 7-vermiculite, 8-gravel and coarse sand, 9-soil with gravel, 10-coarse sand, 11-pebble and gravel, 12-vegetation, 13-feed pump.

with tourism, no tourists residing in the home, and its residents observed a traditional life style; therefore, the water consumption and wastewater properties of this household were representative of a native inhabitant. $\mathrm{BH}$ contained an hotel that had a dining hall, but no shower. $\mathrm{CH}$ contained an hotel with a shower facility. DH was a restaurant without a guest room. The quantity of water consumption by each of the four households was investigated from May 31, 2007 to June 7,2007 , and the results are presented in Table 1.

As Table 1 shows, the per capita water consumption in 1 day (PCWCD) in the aboriginal household $(\mathrm{AH})$ ranged from 6.25 to $203.75 \mathrm{~L} / \mathrm{p}$ - day, and the average PCWCD during the survey period was $85 \mathrm{~L} / \mathrm{p} \cdot$ day, which is far less than the $200 \mathrm{~L} / \mathrm{p}$ - day of urban household water consumption quota (Chen, 2001). BH, had a PCWCD that ranged from 80 to $100 \mathrm{~L} / \mathrm{p}$ - day according to the number of guests in the hotel and restaurant. $\mathrm{CH}$, had a PCWCD that ranged from 140 to $356 \mathrm{~L} / \mathrm{p}$-day, with an average PCWCD of $193 \mathrm{~L} / \mathrm{p} \cdot$ day. Based on these findings, the shower water consumption by tourists represents a major portion of the total water consumption in Lige Village. The greatest water consumption of DH resulted from the kitchen, and the average per capita water consumption in one meal in these days was estimated to be $95 \mathrm{~L} / \mathrm{p}$. day. Therefore, meal ser- vice is responsible for a large portion of the total water consumption in Lige Village, and kitchen wastewater is an important component of rural domestic wastewater in tourism areas.

When compared with $\mathrm{AH}, \mathrm{CH}$ consumed more water per person (Table 1), which indicates that the water consumption of tourists is more than that of aborigines. On June 7, the owners of $\mathrm{AH}$ repaired the house and $\mathrm{CH}$ cleaned the sheets, which may have lead to sudden increases in the PCWCD. During this study period, the concentration of COD, $\mathrm{NH}_{4}{ }^{+}-\mathrm{N}$, and TP in the wastewater of Lige Village was 162-242, 28-68, and $3.9-4.9 \mathrm{mg} / \mathrm{L}$, respectively.

The results of this investigation showed that the primary source of pollution in the Lugu Lake Area was rural domestic wastewater and runoff. In addition, it is likely that the quantity of domestic wastewater has been greatly affected by changes in the number of tourists. It has been reported that there can be as many as 1,000 tourists in Lige Village per day between July and August; however, the aboriginal was less than 150, and total quantity of domestic wastewater in Lige Village could be $290 \mathrm{~m}^{3}$ / day (LLTAMC, 2006). But in January, February, March, and December, when there are very few tourists in this village, the quantity of domestic wastewater was less than $100 \mathrm{~m}^{3} /$ day (LLTAMC, 2006).

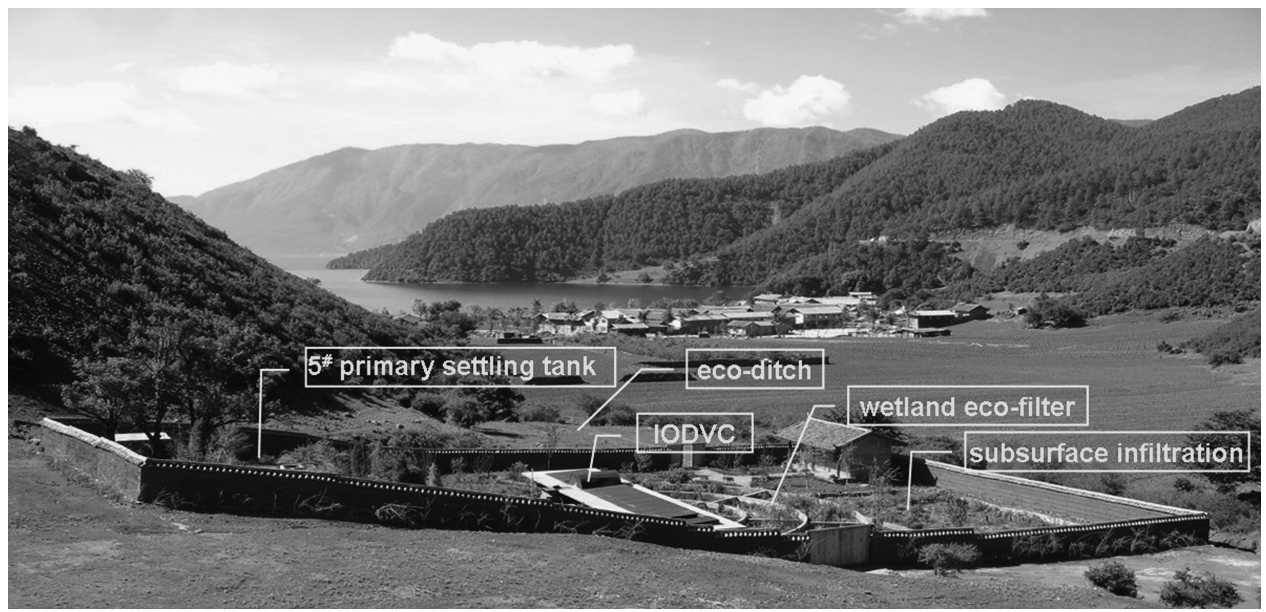

FIG. 5. The full-scale wastewater treatment plant in Lige. 


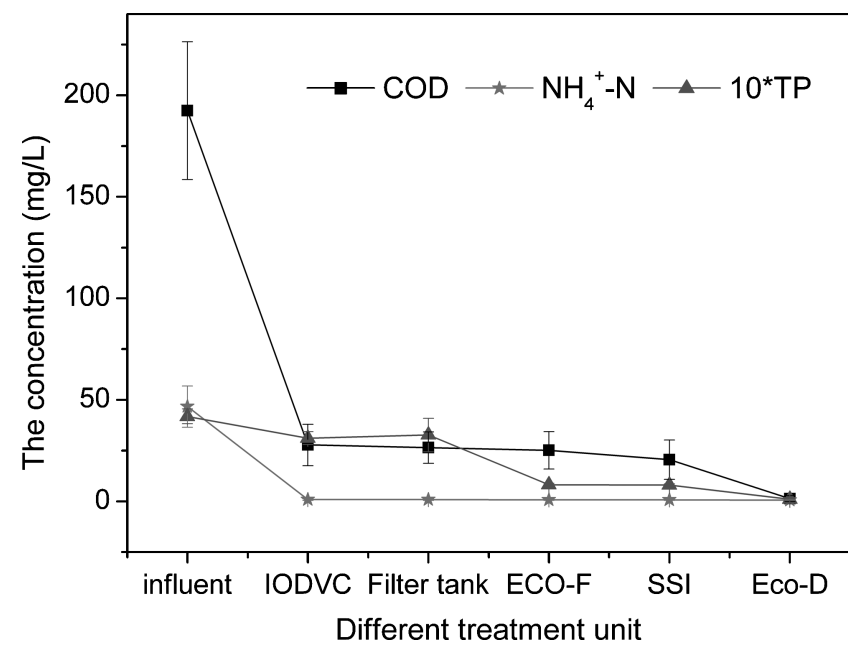

FIG. 6. Removal of chemical oxygen demand (COD), ammonia nitrogen $\left(\mathrm{NH}_{4}{ }^{+}-\mathrm{N}\right)$, and total phosporus (TP) in different treatment units. Eco-F, eco-filter; SSI, subsurface infiltration; Eco-D, eco-ditch (note: TP concentrations displayed have been multiplied by 10 ).

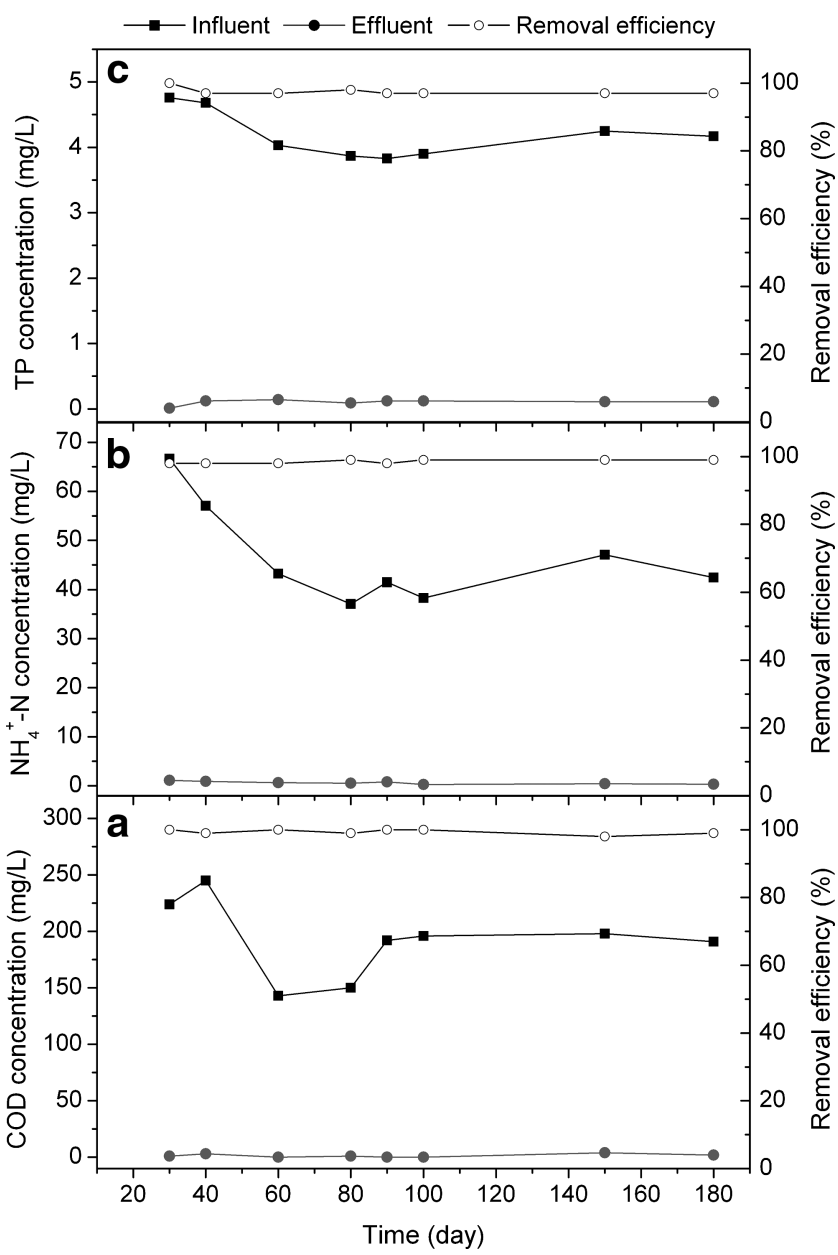

FIG. 7. The long-term performance of bio-eco combined system. (a) COD, (b) $\mathrm{NH}_{4}{ }^{+}-\mathrm{N}$, (c) TP.

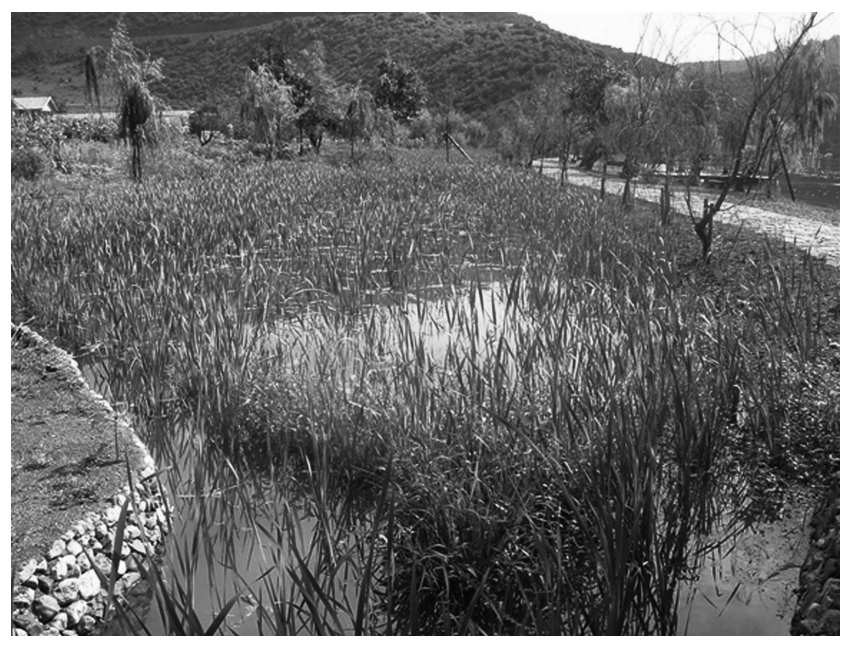

FIG. 8. Eco-wetland for landscape in Lige Village.

\section{Design of a full-scale plant for rural wastewater treatment}

Wastewater collection system. A wastewater collection and treatment system were constructed in Lige Village to protect Lugu Lake from aquatic pollution. In this system, domestic wastewater is first transferred to a septic tank, after which it is transported to the full-scale plant through a sewage pipe. Due to the decentralized distribution of households and the high variation on the quantity of wastewater, a septic tank was constructed for each household and five primary settling tanks were constructed near the sewage pipes and the fullscale plant (\#1-\#5 in Fig. 3). The total volume of the five primary settling tanks was $270 \mathrm{~m}^{3}$. The effluent from the septic tanks in each household was transferred to the nearest primary settling tank along the sewage pipe. The wastewater in tanks \#1 and \#2 was then transferred to tank \#3, after which the wastewater in tanks \#3 and \#4 was pumped into tank \#5, which was located at the full-scale plant.

Bio-eco combined system for rural wastewater treatment. Based on the results of previous studies, a novel bio-eco technology combined system for rural wastewater treatment, which can adapt the rural wastewater properties and satisfy environmental quality requirements in the tourism area, was developed (Fig. 4). The system developed here contained an IODVC as the biological treatment unit as well as a wetland eco-filter, subsurface infiltration, and eco-ditch as an ecological treatment unit. A filter tank was placed between the IODVC and eco-filter to prevent the suspended solids (SS) in the effluent of IODVC from blocking the ecofilter. Compared with the conventional oxidation ditch, the IODVC has the advantage of providing vertical circle, a reaction zone combined with clarifier and an automatic sludge return, which results in the required land area being reduced by $50 \%$ (Guo, 2006). A laboratory-scale and pilot-scale experiment were carried out, and the results revealed that the IODVC was easy to operate and maintain, cost effective, and energy saving. Moreover, the IODVC had powerful resistance to high impact loads (Xia and Liu, 2004; Guo et al., 2007). Through adjusting the speed of the rotating brush, the hydraulic retention time could be saved when the sudden quantity increasing occurred. The filter tank contained ho- 
Table 2. Physicochemical Properties of the Raw Soil

\begin{tabular}{|c|c|c|c|c|c|c|c|c|c|c|c|}
\hline \multirow[b]{2}{*}{ Parameters } & \multirow[b]{2}{*}{$p H$} & \multirow[b]{2}{*}{$\begin{array}{l}O M \\
(\%)\end{array}$} & \multirow[b]{2}{*}{$\begin{array}{c}B E T \\
\left(m^{2} / g\right)\end{array}$} & \multirow[b]{2}{*}{$\begin{array}{c}\text { Available } \\
P(m g / k g)\end{array}$} & \multicolumn{5}{|c|}{ Total metals } & \multicolumn{2}{|c|}{ oxalic acid-ammonium oxalate } \\
\hline & & & & & $\begin{array}{c}F e \\
(\%)\end{array}$ & $\begin{array}{c}A l \\
(\%)\end{array}$ & $\begin{array}{l}\mathrm{Ca} \\
(\%)\end{array}$ & $\begin{array}{c}M g \\
(m g / k g)\end{array}$ & $\begin{array}{c}M n \\
(m g / k g)\end{array}$ & $\begin{array}{c}F e_{o x} \\
(m g / k g)\end{array}$ & $\begin{array}{c}A l_{o x} \\
(m g / k g)\end{array}$ \\
\hline Raw soil & 5.46 & 1.11 & 38.77 & 3.94 & 10.85 & 8.41 & 0.17 & 1247 & 1125 & 4674 & 2679 \\
\hline
\end{tabular}

$\mathrm{OM}$, organic matter.

mogenizing ceramisite (D: $2 \mathrm{~mm}$ ), which is good at intercepting SS and easily backwashed. The ecological method for wastewater treatment had low operating costs and is easy to maintain ( $\mathrm{Li}$ et al., 2003). The wetland eco-filter, which possesses the virtue both wetland and filter, had a synthetical function of plants-adsorb and filtration intensified through reconstructing the multi media (pebble, D: $20-40 \mathrm{~mm}$; gravel D: $20 \mathrm{~mm}$; coarse sand, D: $3-4 \mathrm{~mm}$; local soil) in the filter layers. Pebble (D: $20-40 \mathrm{~mm}$ ), stones (D: $20-40 \mathrm{~mm}$ ) and local soil were used as the medium in the subsurface infiltration unit, and the $\mathrm{P}$ in the wastewater was removed via adsorption by the soil. The local vegetation planted in this unit can strengthen $\mathrm{P}$ and beautify the environment. The designed hydraulic retention time (HRT) in these two treatmentS was 1 day, respectively. The eco-ditch contained soil, microorganism, and plants, which provide further purification. The full-scale wastewater treatment plant was constructed at the foot of a hill behind the major portion of the village to preserve the overall landscape of Lige Village. In addition, the local terrain was utilized in the design, which resulted in substantial cost reductions. Moreover, a flood ditch with the length $200 \mathrm{~m}$ was utilized as the eco-ditch.

\section{Performance of the full-scale wastewater treatment system}

The full-scale wastewater treatment plant was shown in Fig. 5. The activated sludge from a nearby domestic wastewater treatment plant was used to inoculate the IODVC to reduce the start-up time. In the IODVC, the HRT was $13.4 \mathrm{~h}$ (including $1.4 \mathrm{~h}$ in the clarifier), the DO was maintained at 1.0$2.0 \mathrm{mg} / \mathrm{L}$ and the sludge concentration was approximately $2 \mathrm{~g} / \mathrm{L}$. The filter tank was backwashed approximately twice a week and the backwashing water was pumped into tank \#5. Perforated pipe was used to distribute water in the wetland eco-filter and subsurface infiltration units. In addition, safety measures were included in case of blocking, and watered the plants one or two times in a week.

The removal efficiency of COD, $\mathrm{NH}_{4}{ }^{+}-\mathrm{N}$, and TP by the bio-eco combined system in 6 months is shown in Fig. 6. The average removal rate was calculated in each treatment unit. In the IODVC, $85.7 \%$ COD and $97.6 \% \mathrm{NH}_{4}{ }^{+}-\mathrm{N}$ were removed, with the effluent $27.8 \pm 10.1 \mathrm{mg} / \mathrm{L}$ and $0.62 \pm 0.28 \mathrm{mg} / \mathrm{L}$, respectively. But the removal efficiency of TP was only $25.2 \%$. As the effluent from the IODVC flowed through the wet ecofilter, subsurface infiltration, and eco-ditch in sequence, the remaining $P$ in the wastewater was further removed (Fig. 6).

The results of continuous long-term operation in 180 days are shown in Fig. 7. In the final effluent after the eco-ditch, the concentration of COD, $\mathrm{NH}_{4}{ }^{+}-\mathrm{N}$ and TP was less than 10, 1 , and $0.1 \mathrm{mg} / \mathrm{L}$, respectively. The effluent quality reached up to Grade III of environmental quality standards for surface water (MEPPRC and GAQSIQPRC, 2002), and could be recycled in the landscape eco-wetland that was located next to Lugu Lake (Fig. 8).

\section{Evaluation the ability of soil to adsorb $P$}

The primary $\mathrm{P}$ removal process occurred in the ecological treatment units (Fig. 6), and the mechanism of $P$ removal was studied by investigating the ability of local soil to adsorb $\mathrm{P}$. To accomplish this, the physicochemical characteristics of the raw soil and $P$ fractions in both raw soil and saturated soil were analyzed (Tables 2 and 3). The local soil was red and acidic, with a $\mathrm{pH}<6$, OM level of $1.11 \%$, and BET specific surface area of $38.77 \mathrm{~m}^{2} / \mathrm{g}$. In the raw soil, the level of total Ca and $\mathrm{Mg}$ were very low, whereas the total $\mathrm{Fe}$ and $\mathrm{Al}$ contents were 10.85 and $8.41 \%$, respectively. The contents of oxalate extractable $\mathrm{Al}\left(\mathrm{Al}_{o x}\right)$ and $\mathrm{Fe}\left(\mathrm{Fe}_{o x}\right)$, which were considered to fix the $\mathrm{P}$ via polymerization and sorption (Nair et al., 1998), were 3.2 and $4.3 \%$ of the total $\mathrm{Al}$ and $\mathrm{Fe}$, respectively. The content of TP in the raw soil was $1,192 \mathrm{mg} / \mathrm{kg}$, of which over $40 \%$ was Residual P (Res-P). Res-P has a high stability and was not easily utilized by biological organisms (Reddy et al., 1995); therefore, the high percentage of Res-P in the raw soil demonstrates that it has not been disturbed by human activity. The available P was only $3.94 \mathrm{mg} / \mathrm{kg}$ in the raw soil, which is considered the extremely low for acidic soil, and indicating that the phosphate fertilizer was scarce (Bao, 2000). After P adsorption experiment, the TP in the saturated soil increased to $2,719 \mathrm{mg} / \mathrm{kg}$; however, the concentration of Res-P was nearly the same as the raw soil (Table 3). As shown in Table 3,

Table 3. Phosphorus Fractions in Raw Soil and Saturate Soil

\begin{tabular}{lcccccc}
\hline & & \multicolumn{4}{c}{ Phosphorus fractions } \\
\cline { 3 - 7 } Soil samples & $T P(m g / k g)$ & $\mathrm{KCl}-\mathrm{P}(\mathrm{mg} / \mathrm{kg})$ & $\mathrm{NaOH}-\mathrm{Pi}(\mathrm{mg} / \mathrm{kg})$ & $\mathrm{NaOH}-\mathrm{Po}(\mathrm{mg} / \mathrm{kg})$ & $\mathrm{Ca}-\mathrm{P}(\mathrm{mg} / \mathrm{kg})$ & $\mathrm{Res}-\mathrm{P}(\mathrm{mg} / \mathrm{kg})$ \\
\hline Raw & 1192 & 3.13 & 205 & 358 & 113 & 512 \\
Saturate & 2719 & 56.64 & 1462.37 & 538.46 & 144.84 & 517 \\
\hline
\end{tabular}


which provides a comparison of the different forms of $\mathrm{P}$ in raw soil and saturated soil, the $\mathrm{NaOH}-\mathrm{Pi}(\mathrm{Fe} / \mathrm{Al}-\mathrm{P})$ was significantly increased, over $80 \%$ of the TP adsorbed. These findings indicate that the $\mathrm{P}$ was primarily adsorbed by fixation of $\mathrm{Fe}$ and $\mathrm{Al}$ in this acidic soil.

\section{Cost analysis of the project}

Since normal operation of the full-scale plant, the capacity treating wastewater has generally been around $100 \mathrm{~m}^{3} /$ day. Therefore, the costs of operation and maintenance were estimated based on the wastewater quantity of $100 \mathrm{~m}^{3} /$ day.

Power consumption. A rotating-brush (Rated Power: $2.2 \mathrm{~kW}$ ) controlled by a frequency modulation motor supplies the DO in the IODVC. The energy required to operate this system for per cubic meter wastewater is $0.422 \mathrm{kWh} / \mathrm{m}^{3}$, and the price of electricity is currently $0.6 \mathrm{CNY} / \mathrm{kWh}(0.088 \$ /$ $\mathrm{kWh})$; therefore, the cost of electricity is calculated to be 0.253 $\mathrm{CNY} / \mathrm{m}^{3}\left(0.037 \$ / \mathrm{m}^{3}\right)$. In addition, a pump for backwashing (rated power: $0.5 \mathrm{~kW}$ ), was operated approximately $20 \mathrm{~min}$ per week, then the power consumption per year is $9 \mathrm{~kW}$. Therefore, the cost associated with this pump can be neglected duo to the annual consumption is less than 10 CNY (1.46\$).

Labor cost. One operator with a salary of $400 \mathrm{CNY}$ (58.48 \$) per month translates to a labor cost of $0.133 \mathrm{CNY} / \mathrm{m}^{3}$ $\left(0.019 \$ / \mathrm{m}^{3}\right)$.

Thus, the total cost of per cubic meter of wastewater, which is the cost of power consumption and labor cost, is $0.386 \mathrm{CNY} / \mathrm{m}^{3}\left(0.056 \$ / \mathrm{m}^{3}\right)$.

\section{Conclusions}

1. In this investigated tourism region, the rural wastewater quantity was found to have great relationship with the tourists, which resulted in the difference between tourism and nontourism seasons; moreover, the inflow fluctuation was intensive. The water consumption of the tourists was much higher than that of original residents, and the bath and kitchen wastewater were the major parts of the domestic wastewater. In addition, the life style and customs of the residents were influenced by the tourists, which leaded to water consumption increasing.

2. The primary settling tank played an important role of collecting wastewater and adjusting inflow. A novel bio-eco combined system developed for this study performed very well with the concentrations of COD, $\mathrm{NH}_{4}{ }^{+}-\mathrm{N}$, and $\mathrm{TP}$, and in the final effluent were less than 10,1 , and $0.1 \mathrm{mg} / \mathrm{L}$, respectively. In addition, the bioeco combined technology wastewater treatment plant developed here made full use of the terrain features, which reduced the investment and operation costs.

3. More than $65 \%$ TP was absorbed and removed in the eco units. Local soil belonged to acidic soil, and $\mathrm{Fe} \%$ and $\mathrm{Al} \%$ were abundant. The iron and aluminum oxides in the soil had great contribution to P removal, and more than $80 \%$ adsorbed $\mathrm{P}$ existed in $\mathrm{Fe} / \mathrm{Al}-\mathrm{P}$.

4. The full-scale bio-eco combined system had the characteristics of high-efficiency, cost-effective, easy maintenance and good landscape fit, that could be applied in rural areas in China.

\section{Acknowledgments}

This work was supported by the National High Technology Research and Development Program of China (863 Program) (No. 2004AA601070) and Research Center for EcoEnvironmental Sciences (RCEES-QN-200713).

\section{Author Disclosure Statement}

The authors declare that no conflicting financial interests exist.

\section{References}

APHA. (1998). Standard Methods for the Examination of Water and Wastewater, 20th ed. Washington, DC: American Public Health Association/American Water Works Association/Water Environment Federation.

Bai, Y.G., and Wu, H.T. (2005). Primary study of technology for rural domestic sewage treatment in the Lake Taihu area. Electric Power Environ. Protect. 21, 44.

Bao, S.D., Ed. (2000). Chemical Analysis for Agricultural Soil. Beijing: China Agriculture Press.

Chen, X.S., Ed. (2001). Building Water and Wastewater. Beijing: China Architecture and Industry Press.

Guo, X.S. (2006). An integrated system for wastewater treatment-Sludge reduction and its hydrodynamics, Ph.D. thesis. Research Center for Eco-Environmental Sciences, Chinese Academy of Sciences.

Guo, X.S., Liu, J.X., Wei, Y.S., and Li, L. (2007). Sludge reduction with Tubificidae and the impact on the performance of the wastewater treatment process. J. Environ. Sci. 19, 257.

Hellstrom, D., and Jonsson, L. (2003). Evaluation of small wastewater treatment systems. Water Sci. Technol. 48, 61 .

Ho, G. (2003). Small water and wastewater systems: pathways to sustainable development? Water Sci. Technol. 48, 7.

Kavanagh, L.J., and Keller, J. (2007). Engineered ecosystem for sustainable on-site wastewater treatment. Water Res. 41, 1823.

Kong, G., Xu, Z.Y., Wang, Y., Tie, J.X., and Zheng, Z. (2006). Influence of technical construction of infiltration trench on nitrogen and phosphorus removal. Environ. Sci. Techno. 29, 7.

Li, T.W., Peng, Y.Z., Wang, Y.Y., Zhu, G.B., Chi, W.Q., and Gu, G.W. (2003). Experimental study on sequencing batch biofilm reactor with biological filtration (SBBR-BF) for wastewater treatment. Water Sci. Technol. 48, 299.

Liu, C.M., and Chu, J.Y. (2007). Application of SBR in rural domestic sewage. J. Agricult. Mech. Res. 6, 229.

LLTAMC. (2006). The introduction of Lugu Lake Tourism Industry Development, Lijiang. Lijiang, Yunnan Province, China: Lugu Lake Tourism Area Management Committee.

MEPPRC and GAQSIQPRC. (2002). GB 3838-2002 (Environmental Quality Standards for Surface Water). Beijing: Ministry of Environmental Protection of the People's Republic of China and General Administration of Quality Supervision Inspection and Quarantine of the People's Republic of China.

MGMPRC. (1994). GB 14848-9 (Quality Standard of Ground Water). Beijing: Ministry of Geology and Mineral, People's Republic of China (MGMPRC).

MHURDPRC. (2005). Present Situation and Problems of Rural Human Settlements. Beijing: Ministry of Housing and UrbanRural Development of the People's Republic of China (MHURDPRC). 
Moore, P., and Coale, F. (2004). Phosphorus fractionation in flooded soils and sediments. In G.M. Pierzynski, Ed., Methods for P Analysis. Raleigh, NC: North Carolina State University.

Moore, P.A., and Reddy, K.R. (1994). Role of Eh and pH on phosphorus geochemistry in sediments of Lake Okeechobee, Florida. J. Environ. Qual. 23, 955.

Nair, V.D., Graetz, D.A., and Reddy, K.R. (1998). Dairy manure influences on phosphorus retention capacity of spodosols. J. Environ. Qual. 27, 522.

NBSC. (2007). The Statistical Yearbook of Lijiang-2006. Beijing: National Bureau of Statistics of China (NBSC).

Oladoja, N.A., and Ademoroti, C.M.A. (2006). The use of fortified soil-clays as on-site system for domestic wastewater purification. Water Res. 40, 613.

Pierzynski, G.M. (2000). Methods of Phosphorus Analysis for Soils, Sediments, Residuals and Waters. Raleigh, NC: North Carolina State University.
Quan, X.C., Yang, Z.F., and Tang, Q. (2005). Development and application of decentralized treatment technology for domestic sewage. China Water Wastewater 21, 24.

Reddy, K.R., Diaz, O.A., Scinto, L.J., and Agami, M. (1995). Phosphorus dynamics in selected wetlands and streams of the Lake Okeechobee Basin. Ecol. Eng. 5, 183.

Tang, Z.J., Chu, J., Zhang, L., and Cui, J.Q. (2008). Study on ecological control model and technologies in rural water environment. Pollut. Control Technol. 21, 37.

Tessier, A., Campbell, P.G.C., and Bisson, M. (1979). Sequential extraction procedure for the speciation of particulate trace metals. Anal. Chem. 51, 844.

Voorthuizen, E.M.V., Zwijnenburg, A., and Wessling, M. (2005). Nutrient removal by NF and RO membranes in a decentralized sanitation system. Water Res. 39, 3657.

Xia, S.B., and Liu, J.X. (2004). An innovative integrated oxidation ditch with vertical circle for domestic wastewater treatment. Process Biochem. 39, 1111. 
